\title{
Changes in fatty acid composition of Stenotrophomonas maltophilia KB2 during co-metabolic degradation of monochlorophenols
}

\author{
Agnieszka Nowak $^{1} \cdot$ Izabela Greñ $^{1} \cdot$ Agnieszka Mrozik $^{1}$
}

Received: 14 July 2016/Accepted: 14 October 2016/Published online: 18 October 2016

(c) The Author(s) 2016. This article is published with open access at Springerlink.com

\begin{abstract}
The changes in the cellular fatty acid composition of Stenotrophomonas maltophilia KB2 during cometabolic degradation of monochlorophenols in the presence of phenol as well as its adaptive mechanisms to these compounds were studied. It was found that bacteria were capable of degrading 4-chlorophenol (4-CP) completely in the presence of phenol, while 2-chlorophenol (2-CP) and 3 -chlorophenol (3-CP) they degraded partially. The analysis of the fatty acid profiles indicated that adaptive mechanisms of bacteria depended on earlier exposure to phenol, which isomer they degraded, and on incubation time. In bacteria unexposed to phenol the permeability and structure of their membranes could be modified through the increase of hydroxylated and cyclopropane fatty acids, and straight-chain and hydroxylated fatty acids under 2-CP, 3-CP and 4-CP exposure, respectively. In the exposed cells, regardless of the isomer they degraded, the most important changes were connected with the increase of the contribution of branched fatty acid on day 4 and the content of hydroxylated fatty acids on day 7 . The changes, particularly in the proportion of branched fatty acids, could be a good indicator for assessing the progress of the degradation of monochlorophenols by S. maltophilia KB2. In comparison, in phenol-degrading cells the increase of cyclopropane and straight-chain fatty acid content was established. These findings indicated the degradative potential of the tested strain towards the co-metabolic degradation of persistent chlorophenols, and extended the
\end{abstract}

Agnieszka Nowak

agnieszka.a.nowak@us.edu.pl

1 Department of Biochemistry, Faculty of Biology and Environmental Protection, University of Silesia, Jagiellońska 28, 40-032 Katowice, Poland current knowledge about the adaptive mechanisms of these bacteria to such chemicals.

Keywords Co-metabolism - Fatty acid composition . Monochlorophenols · Stenotrophomonas maltophilia KB2

\section{Introduction}

Chlorophenols and their derivatives are ubiquitous contaminants of air, water and soil. They enter the environment through human activities, such as waste incineration, the use of wood preservatives, leather conditioners, solvents, dyes, pesticides and antiseptics, as well as the bleaching of pulp with chlorine (Czaplicka 2004). Due to their high toxicity, strong emissions, persistence in the environment and suspected carcinogenic and mutagenic properties, over recent decades chlorophenols have become quantitatively significant contaminants, listed as priority pollutants by the Agency for Toxic Substances and Disease Registry (ATSDR) and the World Health Organization (WHO).

The fate of chlorophenols in the environment is of great importance and should be constantly monitored. The uncontrolled release of these chemicals with effluents and residues from industrial plants affects the continuous contamination of air, water, soil and sediments, and as a consequence threatens human health (Michałowicz and Duda 2007). This causes a real risk of chronic exposure of living organisms to these compounds, and therefore their disposal and degradation have become a serious challenge. Several physical and chemical methods, including activated carbon adsorption, ion exchange and incineration, have been proposed for treating or recovering chlorophenolic compounds (Hamdaoui and Naffrechoux 2007; 
Bakhtiar et al. 2011). They are effective but expensive, and can lead to the formation of more harmful intermediates. An alternative to such methods seems to be microbial degradation (Pandey et al. 2009; Mrozik and PiotrowskaSeget 2010). Although biological treatments of chlorophenols with specialized microorganisms are documented in the literature, their use on a large scale is still limited (Balfanz and Rehm 1991; Männistö et al. 2001; Caliz et al. 2011).

The pollution of various environments by a single contaminant is quite rare. More frequently they are contaminated with a mixture of substances with different physicochemical properties and susceptibility to biodegradation (Brack et al. 2003; Antizar-Ladislao et al. 2008; Li et al. 2013). When chlorophenols are present in the mixture and the additional carbon sources are available, their cometabolic degradation may be possible (Hazen 2010; Vrchotová et al. 2013). The co-substrates can be either the conventional carbon sources supporting cell growth, or the structural analogue compounds inducing the catabolic enzymes (Lee and Lee 2007; Bhatkal et al. 2012).

Among living organisms bacteria have a unique ability to adapt to changing environmental factors, including chemical stress. In response to exposure to harmful compounds, they can modify the structure and fluidity of the cytoplasmic membrane, the first site of contact between cell and chemicals. In the presence of aromatic compounds the changes in saturation degree, length of acyl chains, isomerisation of cis to trans unsaturated fatty acids, and alterations in the content of cyclopropane, hydroxylated and branched fatty acids in the bacterial membrane are well documented (Duldhardt et al. 2010; Segura et al. 2010; Smułek et al. 2015). The increase in membrane saturation proceeds only in the growing cells as the effect of the de novo biosynthesis of saturated fatty acids, and thus it can be a potential marker of harmful effects of chemicals on living cells (Murínová and Dercová 2013). A similar effect, independent of cell growth, is observed when trans-unsaturated fatty acids are incorporated into the membrane in a place of cis-unsaturated fatty acids. Cis to trans isomerisation catalysed by cis-trans isomerase is observed less than $10 \mathrm{~min}$ after the contact of cells with the toxic compound, and therefore it is considered a very rapid adaptation mechanism (Heipieper et al. 2003; Bernal et al. 2007). The increase of membrane polarity may be achieved by the increase of hydroxylated acid content. It is generally known that 3-hydroxyl fatty acids are typical intermediates in fatty acid synthesis (López-Lara and Geiger 2010). Conversely, the $S$-2-hydroxylation catalysed by LpxO dioxygenase is post-synthetic modification, usually observed when the fatty acyl group binds to the lipid A molecule (Gibbons et al. 2008). Cyclopropanation of cisunsaturated fatty acids is also a post-synthesis process. Cyclopropane fatty acids are formed by the addition of a methylene group, derived from $S$-adenosyl methionine to the carbon-carbon double bond of unsaturated fatty acids (Segura et al. 2010). It is commonly believed that cyclopropane rings are less reactive than double bonds in their precursors, and the increase of cyclopropane fatty acid abundance has the same effect as the increase in bilayer thickness, and therefore it makes the membrane less permeable (Chang and Cronan 1999). The content of branched fatty acids is also changed in bacteria in the presence of aromatic compounds. The alterations in the ratio of iso to anteiso branched fatty acids connected with different transition temperatures and stereospecificity of these isomers also affect membrane fluidity (Unell et al. 2007).

The aim of this study was to investigate the composition of the cellular fatty acids of Stenotrophomonas maltophilia KB2 during the co-metabolic degradation of monochlorophenols in the presence of phenol as an additional carbon source in batch cultures. It was also interesting to find out if the earlier contact of bacteria with phenol could affect the course of co-metabolic degradation of monochlorophenols and cause significant alterations in fatty acid methyl ester (FAMEs) profiles as compared to the unexposed cells. After a detailed analysis of fatty acid patterns, the adaptive mechanisms of KB2 to the presence of phenol and monochlorophenols have been proposed.

\section{Materials and methods}

\section{Bacterial strain and culture conditions}

The bacterial strain used in this study was Stenotrophomonas maltophilia KB2 (VTT E-113197). It is an aerobic, motile, nonfermentative Gram-negative bacterium, isolated from activated sludge of a sewage treatment plant in BytomMiechowice (Poland) and described by Guzik et al. (2009) S. maltophilia $\mathrm{KB} 2$ is known to metabolise broad range of aromatic compounds including phenol, some chloro- and methylphenols, benzoic acids, catechols and others.

In the present study, to assess if the presence of phenol (P) can accelerate the degradation of monochlorophenols, bacteria were grown for 7 days in a mineral salts medium (Mrozik et al. 2007) containing two carbon sources-a proper isomer (2-CP, 3-CP or 4-CP) as the non-growth substrate and $\mathrm{P}$ as the growth substrate. Each monochlorophenol was added to the culture medium at a concentration of $130 \mathrm{mg} \mathrm{l}^{-1}$. To obtain the molar ratio of 3:1 between the growth and the nongrowth substrate, $\mathrm{P}$ was added to the medium at a concentration of $280 \mathrm{mg} \mathrm{l}^{-1}$. Such ratio was considered as the most appropriate for the co-metabolic degradation of chlorophenols in comparison with the other studied $(1: 1,2: 1,3: 1,4: 1$ and 5:1) (data not shown). When growth or non-growth substrate depletion was confirmed, its subsequent identical dosage was 
added to the culture. Additionally, the influence of earlier exposure of bacteria to $\mathrm{P}$ on their capability to degrade cometabolically each monochlorophenol was studied. According to Hao et al. (2002), phenol can induce enzymes responsible for the biodegradation of the non-growth substrate. The exposed cells were cultivated in a medium (Mrozik et al. 2007) supplemented with $P$ as a sole carbon source at a concentration of $282 \mathrm{mg} \mathrm{l}^{-1}$. However, the cells cultured in the nutrient broth (Sigma-Aldrich) without contact with P were treated as unexposed cells. The initial number of bacteria regardless of the culture conditions was $5 \times 10^{8} \mathrm{ml}^{-1}$. All cultures were carried out in $500 \mathrm{ml}$ flasks on a rotary shaker (130 rpm) at $30{ }^{\circ} \mathrm{C}$.

The microbial counts were determined by the dilution plate count technique using nutrient agar (Sigma-Aldrich). The inoculated plates were incubated at $30^{\circ} \mathrm{C}$ for $48 \mathrm{~h}$. The number of bacteria was expressed as $\log \mathrm{CFU} \mathrm{ml} \mathrm{ml}^{-1}$. Data are representative of three individual experiments.

\section{Determination of aromatic compounds concentration}

The aromatic compounds (P, 2-CP, 3-CP and 4-CP) were determined by a Merck Hitachi HPLC equipped with an Ascentis ${ }^{\circledR}$ Express C18 HPLC Column $(100 \times 4.6 \mathrm{~mm})$, Opti-Solw $^{\circledR}$ EXP precolumn and a DAD detector (Merck Hitachi). The mobile phase was a mixture of acetonitrile, methanol and $1 \%$ acetic acid (20:20:60, v/v/v). The flow rate was $1 \mathrm{ml} \mathrm{min}^{-1}$. Chemical compounds in the supernatant were identified and quantified by comparing HPLC retention times and UV-visible spectra with those of external standards. The detection wavelength for the detection of $\mathrm{P}$ and monochlorophenols was set at $272 \mathrm{~nm}$.

\section{Catechol 2,3-dioxygenase activity assay}

Parallel to the degradation study, the activity of catechol 2,3-dioxygenase [EC 1.13.11.2] in S. maltophilia KB2 cells was measured. The preparation of crude extract for enzyme activity assay was performed according to Wojcieszyńska et al. (2013). Catechol 2,3-dioxygenase activity was estimated by the spectrophotometric method (Hegeman 1966) using catechol as a substrate in a reaction mixture. The specific activity of the enzyme was expressed as the number of enzyme units per milligram of protein. The protein concentration in the crude extract was determined by the Bradford method (Bradford 1976) using lysozyme as a standard.

\section{MIDI-FAME analysis}

To determine the composition of the whole-cell derived fatty acids of $S$. maltophilia KB2, FAMEs were directly extracted from phenol-degrading bacteria and control cells (cultivated in nutrient broth) in the late exponential phase of growth (after $6 \mathrm{~h}$ ) as well as from the batch cultures conducted under co-metabolic conditions on 1, 4 and 7 day. Bacteria were harvested by centrifugation $(4500 \mathrm{~g}$, $20 \mathrm{~min}, 4^{\circ} \mathrm{C}$ ), and next the pellets were washed with $0.9 \% \mathrm{NaCl}$ to remove the residue of the culture medium. Fatty acids were extracted according to the procedure by Sasser (1990) and identified using the Microbial Identification System (MIS; Microbial ID Inc., Newark). FAMEs were separated with a gas chromatograph (Hewlett-Packard 6890) equipped with an HP-Ultra 2 capillary column (25 m, $0.22 \mathrm{~mm}$ ID) and hydrogen as the carrier gas. FAMEs were detected by a flame ionization detector (FID) and identified using the MIDI Microbial Identification System software (Sherlock TSBA 6.1 method and TSBA6 library; MIDI Inc., Newark, DE, USA).

For the interpretation of the obtained results the identified fatty acids were divided into two groups: saturated (straight-chain, branched, cyclopropane and hydroxylated fatty acids) and unsaturated fatty acids. The subgroup of hydroxylated fatty acids additionally included the hydroxylated, branched fatty acids.

\section{Data analysis}

The results were evaluated by analysis of variance, and statistical analyses were performed on three replicates of data obtained from each treatment. The statistical significance $(p<0.05)$ of differences was treated statistically by two-way ANOVA, considering the effect of substrate and incubation time, and assessed by post hoc comparison of means using the lowest significant differences (LSD) test. The FAMEs profiles were also subjected to principal component analysis (PCA). All data were performed using the Statistica 10.0 PL software package, based on mean values of three replicates.

\section{Results}

\section{Degradation of phenol and chlorophenols by $S$. maltophilia KB2}

As Guzik et al. (2009) demonstrated, the S. maltophilia KB2 strain was not able to degrade monochlorophenols at a concentration of $130 \mathrm{mg} \mathrm{l}^{-1}$ as a single carbon source in the batch cultures. Therefore, its ability to degrade 2-CP, 3-CP and 4-CP in the presence of $\mathrm{P}$ as a growth substrate was tested. At the beginning, the ability of $S$. maltophilia KB2 to degrade phenol (282 $\mathrm{mg} \mathrm{l}^{-1}$ ) was experimentally confirmed. The complete breakdown of $\mathrm{P}$ proceeded within 
$6 \mathrm{~h}$ and it was accompanied by a significant increase in the number of cells (Fig. 1).

The co-metabolic degradation study indicated significant differences in the course of degradation of each monochlorophenol by exposed and unexposed cells. The exposed cells degraded completely the first dose of 4-CP within $12 \mathrm{~h}$. During the next 6 days they removed only $30 \%$ of the second dose. Simultaneously, in the presence of 4-CP S. maltophilia KB2 degraded completely two doses of $\mathrm{P}$. The first one it utilized within $12 \mathrm{~h}$ and the second one within 2 days. The third dose of $\mathrm{P}$ bacteria metabolized in $20 \%$ during the next 4 days (Fig. 2e). Contrary to 4-CP, 2-CP and 3-CP bacteria degraded partially. During the first 7 days KB2 transformed 75 and $25 \%$ of 2-CP and 3-CP, respectively (Fig. 2a, c). Data obtained from a parallel study on the co-metabolic degradation of monochlorophenols by unexposed $S$. maltophilia KB2 indicated the lower degradative potential of such bacteria towards monochlorophenols in comparison with the exposed ones. The unexposed bacteria completely degraded the first dose of 4-CP and $\mathrm{P}$ within 3 days (Fig. 2f), while during the next 4 days they transformed only 20 and $25 \%$ of the second dose of 4-CP and P, respectively. In comparison, the unexposed bacteria transformed $65 \%$ of the initial dose of 2-CP in the presence of $\mathrm{P}$ during 7 days, however they were unable to transform 3-CP (Fig. 2b, d). The highest bacterial counts were estimated in the medium with exposed cells in the presence of 4-CP and P (Fig. 2e), while in the presence of 3-CP and P the number of cells was the smallest (Fig. 2c, d).

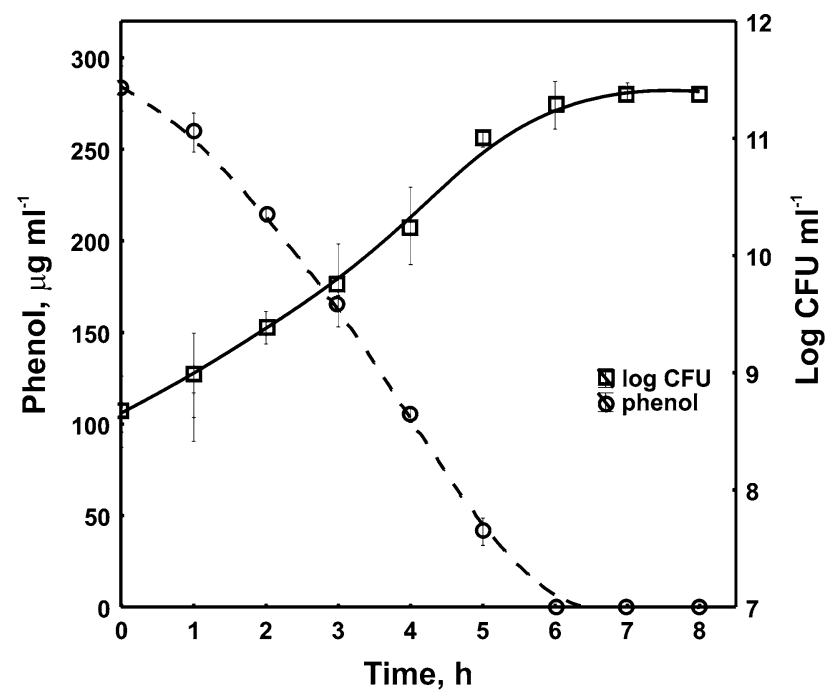

Fig. 1 Degradation of phenol $\left(280 \mathrm{mg} \mathrm{1}^{-1}\right)$ by S. maltophilia KB2 and growth of bacteria. Each symbol represents the mean of three replicates
Fig. 2 Co-metabolic degradation of 2-CP, 3-CP and 4-CP in the presence of $\mathrm{P}$ by $S$. maltophilia $\mathrm{KB} 2$ and survival of bacteria. $\mathbf{a}, \mathbf{c}, \mathbf{e}-$ exposed cells; $\mathbf{b}, \mathbf{d}, \mathbf{f}$ - unexposed cells. Each symbol represents the means of three replicates. Arrows indicate introduction of substrate(s) into the culture

\section{Activity of catechol 2,3-dioxygenase}

As shown in Table 1, the relative activity of catechol 2,3dioxygenase in bacteria culturing with 4-CP and $\mathrm{P}$ reached $81.74 \%$ of its activity in phenol-degrading cells. However, in bacteria co-metabolized 2-CP and $\mathrm{P}$ it was significantly lower $(22.87 \%)$. In turn, the activity of 2,3-dioxygenase in the cells cultured with $3-\mathrm{CP}$ and $\mathrm{P}$ was completely inhibited.

\section{FAMEs analysis}

At first, to illustrate FAME variability in phenol-degrading S. maltophilia KB2 during degradation of $\mathrm{P}$, the whole-cell derived fatty acids were directly extracted from these bacteria and control cells. The detailed analysis of FAME profiles indicated significant increase in the content of cyclopropane and straight-chain fatty acids, with a simultaneous decrease of the unsaturated fatty acids in phenoldegrading cells as compared to the control cells (Fig. 3).

The analysis of FAMEs isolated from S. maltophilia KB2 exposed to $\mathrm{P}$ during the co-metabolic degradation of monochlorophenols indicated that both the earlier exposure of bacteria to $\mathrm{P}$ and the time of incubation affected their fatty acid composition. In bacteria exposed to $\mathrm{P}$, regardless of the isomer added, a remarkable increase in the branched fatty acid content on day 4 was observed. On the last sampling day the increase in the percentage of hydroxylated fatty acids in these bacteria was also significant. The increase in the content of branched and hydroxylated fatty acids was correlated with the reduction in the contribution of cyclopropane and unsaturated fatty acids (Fig. 4a, c, e). The PCA analysis indicated that all FAMEs extracted from bacteria on day 1 were distinct in comparison with the other fatty acids along the first axis, and they were mainly characterized by higher content of $16: 1 \omega 7 c, 18: 1 \omega 7 c$ and 17:0 cy (Fig. 5a, b). Furthermore, the decrease in the percentage of these fatty acids in FAMEs profiles obtained for bacteria on days 4 and 7 was correlated with a simultaneous increase in the content of branched fatty acids 15:0 iso, 15:0 anteiso, 16:0 iso, 17:0 anteiso, and hydroxylated fatty acid 12:0 30H (Fig. 5a, b).

Contrary to the presented results, in the cells unexposed to $\mathrm{P}$ the increase in the degree of membrane saturation was connected with different classes of fatty acids and depended on the type of isomer used. In the presence of 2-CP the 

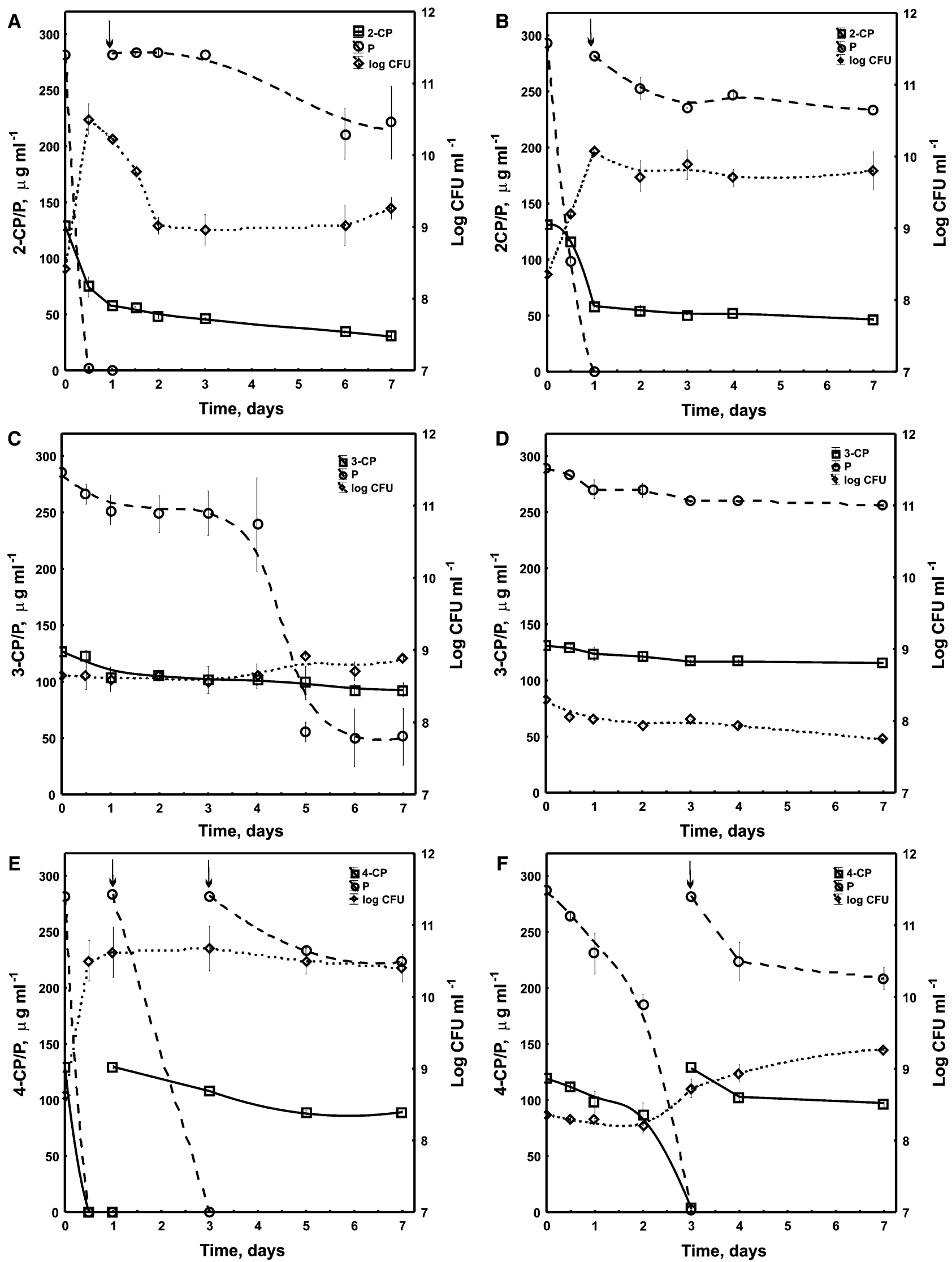
Table 1 Relative activity of catechol 2,3-dioxygenase of $S$. maltophilia $\mathrm{KB} 2$ during transformation of $2-\mathrm{CP}, 3-\mathrm{CP}$ and $4-\mathrm{CP}$ in the presence of $\mathrm{P}$

\begin{tabular}{lc}
\hline Substrate(s) & Relative activity $(\%)$ \\
\hline $\mathrm{P}$ & $100.00 \pm 18.72 \mathrm{a}$ \\
$\mathrm{P}+2-\mathrm{CP}$ & $22.87 \pm 0.63 \mathrm{~b}$ \\
$\mathrm{P}+3-\mathrm{CP}$ & $0.00 \pm 0.00 \mathrm{c}$ \\
$\mathrm{P}+4-\mathrm{CP}$ & $81.74 \pm 2.41 \mathrm{~d}$ \\
\hline
\end{tabular}

The data presented are means of three replicates. The plus/minus values represent standard deviation. The different letters indicate significant differences ( $p<0.05$, LSD test), considering the effects of monochlorophenols on enzymes activity

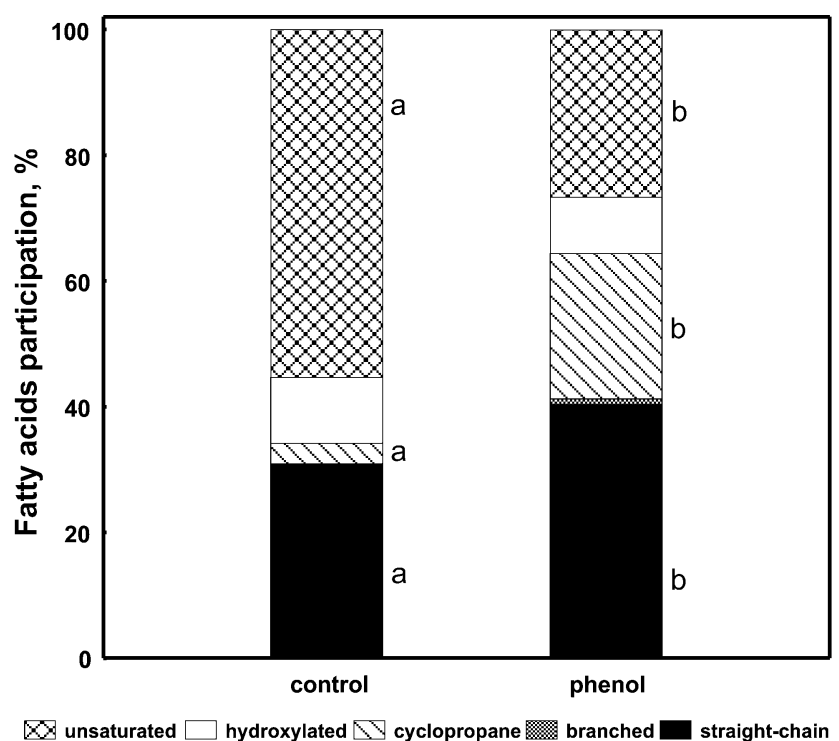

Fig. 3 Proportions of different groups of fatty acids in phenoldegrading S. maltophilia KB2 and control cells. Data are representative of three individual experiments. The different letters indicate significant differences $(p<0.05$, LSD test) considering the effects of the medium

increase in the content of hydroxylated $(10: 03 \mathrm{OH}, 12: 0$ $2 \mathrm{OH}, 12: 03 \mathrm{OH})$ and cyclopropane (17:0 cy) fatty acids on day 4 was recorded (Figs. 4 b and $5 c$, d). At the same time, in the presence of 3-CP a remarkable increase in the percentage of straight-chain $(12: 0,16: 0)$ fatty acids in the FAME pattern was revealed (Fig. $4 d$ and $5 c$, d). In turn, the presence of 4-CP in culture medium caused a remarkable increase in the abundance of hydroxylated fatty acids (10:0 3OH, 12:0 2OH, 12:0 3OH) (Figs. 4f and 5c, d).

\section{Discussion}

The strain Stenotrophomonas maltophilia KB2 was described previously as a good degrader of different monocyclic aromatic hydrocarbons, such as phenol,
Fig. 4 Proportions of different groups of fatty acids in S. maltophilia $\mathrm{KB} 2$ growing in the presence of $2-\mathrm{CP}$ and $\mathrm{P}(\mathbf{a}, \mathbf{b}), 3-\mathrm{CP}$ and $\mathrm{P}(\mathbf{c}, \mathbf{d})$, 4-CP and $\mathbf{P}(\mathbf{e}, \mathbf{f})$ on days 1,4 and 7 . a, $\mathbf{c}, \mathbf{e}$-exposed cells; $\mathbf{b}, \mathbf{d}, \mathbf{f}-$ unexposed cells. The different letters indicate significant differences ( $p<0.05$, LSD test) considering the effects of the incubation period

benzoic acid and its derivatives. However, it was not able to degrade monochlorophenols as a sole carbon source (Guzik et al. 2009). Because co-metabolic degradation of monochlorophenols by KB2 has not been studied extensively, the aim of this research was to investigate this phenomenon as well as to find out and fully explain adaptive mechanisms of bacteria involved the alterations in their cellular fatty acid composition under co-metabolic conditions.

The results of this study indicated that S. maltophilia KB2 was capable of completely degrading 4-CP in the presence of $\mathrm{P}$, while the degradation of 2-CP and 3-CP was incomplete. It was also confirmed that the efficiency of the co-metabolic degradation of monochlorophenols by these bacteria depended on the earlier exposure of bacteria to phenol and the position of the chlorine substituent in the aromatic ring. The exposure of bacteria to the growth substrate allowed them to induce enzymes responsible for the degradation of phenol and in a consequence increased the rate of chlorophenols utilization. It was evidenced that the exposure of bacteria to easily degradable aromatic compounds can accelerate the removal of other hard-todegrade compounds and reduce the time needed for their biodegradation. In another study (Wojcieszyńska et al. 2013) reported that $S$. maltophilia KB2 was able to degrade $90 \%$ of $2-\mathrm{CP}$ added to the medium at a concentration of $65 \mathrm{mg} \mathrm{l}^{-1}$ in the presence of phenol at a concentration of $375 \mathrm{mg} \mathrm{l}^{-1}$ during one week of incubation. Contrary to our studies, they followed the breakdown of 2-CP in the presence of the growth substrate, which was added every $24 \mathrm{~h}$ to the initial level. During this experiment bacteria degraded in total $59 \mathrm{mg}^{-1}$ of $2-\mathrm{CP}$, while in our experiment at the same time they were able to degrade $98 \mathrm{mg} \mathrm{l}^{-1}$ of this compound.

Differences in the activity of catechol 2,3-dioxygenase, the main enzyme induced by phenol as the growth substrate, in the presence of different isomers of monochlorophenols indicated the diverse sensitivity of this enzyme depending on the position of the chlorine substituent in the aromatic ring. The lack of dioxygenase activity in the presence of 3-CP was in an agreement with the negligible co-metabolic degradation of this isomer, while the inhibition of this enzyme about $20 \%$ in comparison with its activity in phenol-degrading bacteria did not affect the degradation of 4-CP. The competitive inhibition of catechol 2,3-dioxygenase by 2-CP and 4-CP was also confirmed by Wojcieszyńska et al. (2013). Similarly, 

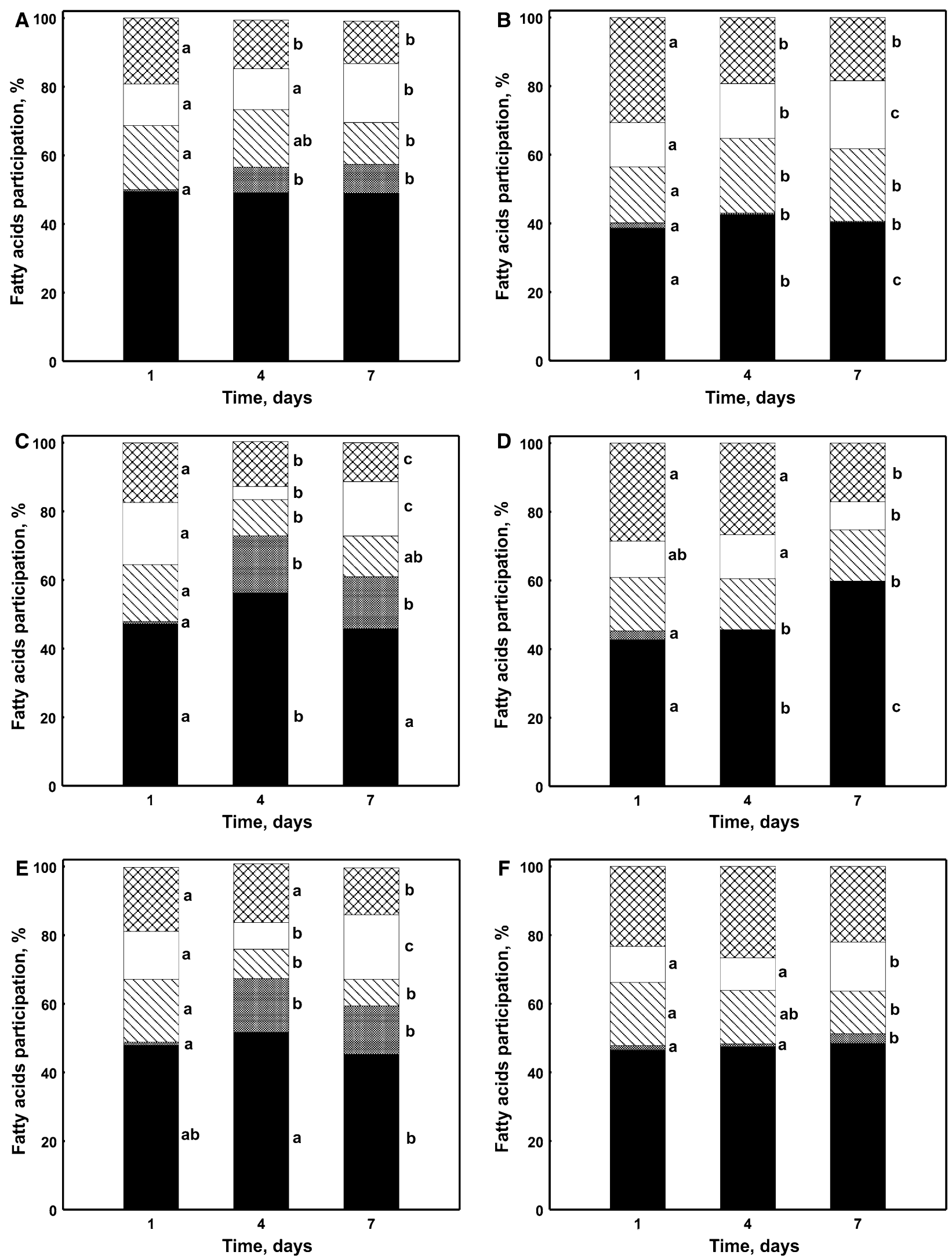

$\otimes$ unsaturated $\square$ hydroxylated $\triangle$ cyclopropane $\square$ branched $\square$ straight-chain 

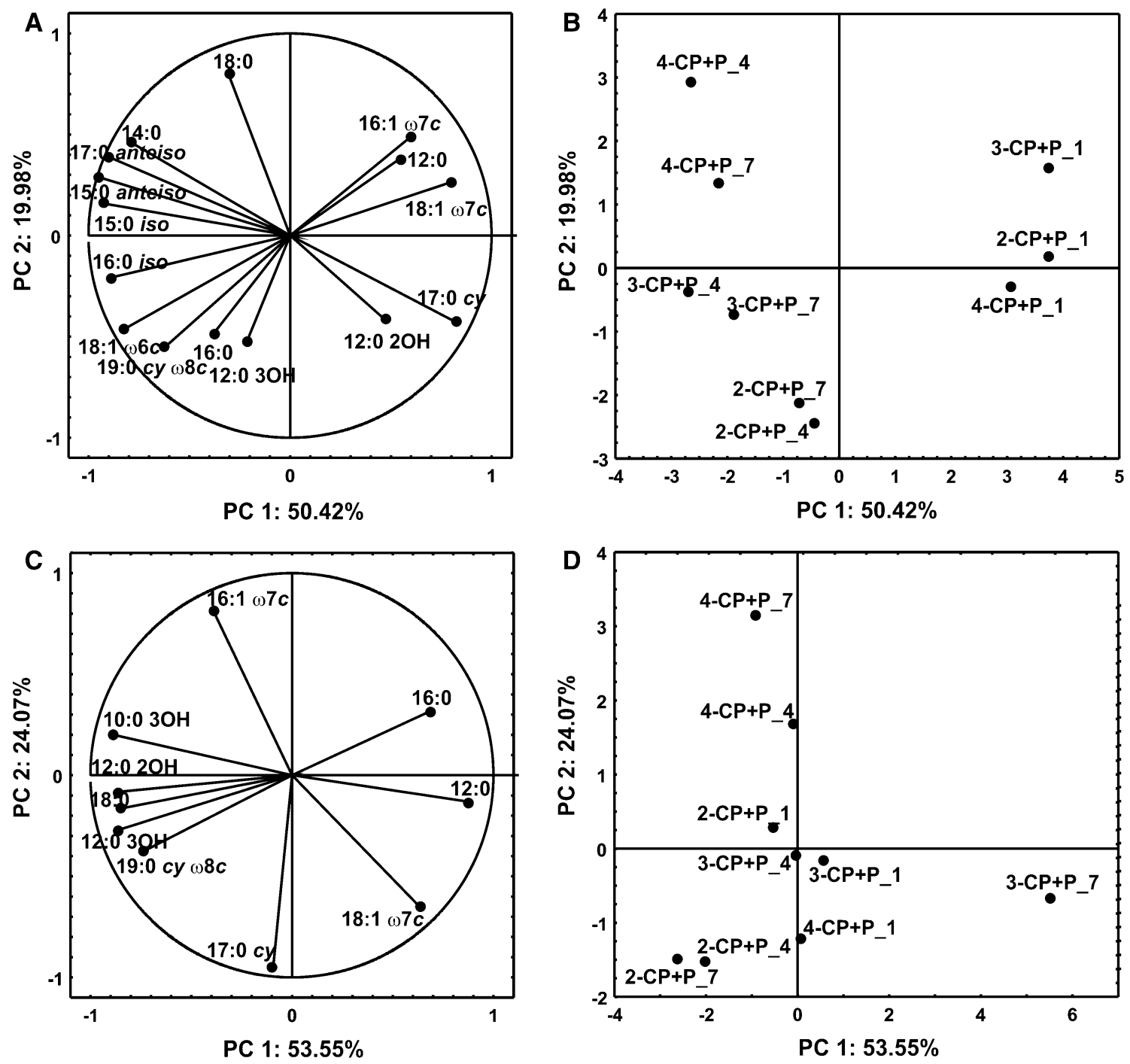

Fig. 5 PCA of FAMEs during co-metabolic transformation of monochlorophenols in the presence of $\mathrm{P}$ by $S$. maltophilia KB2. a, b-exposed cells; $\mathbf{c}, \mathbf{d}-$ unexposed cells. a, c-correlation of fatty acids with $\mathrm{PC} 1$ and $\mathrm{PC} 2 ; \mathbf{b}, \mathbf{d}$-projection of FAMEs on the plane

the ability of the Alcaligenes sp. A7-2 strain to degrade phenols in order $\mathrm{P}>4-\mathrm{CP}>2-\mathrm{CP}>3-\mathrm{CP}$ was observed by Menke and Rehm (1992). They connected this order with the configuration of hydroxyl and the chloride substituent in the aromatic ring and the facility of the introduction of the second hydroxyl group into the substrate. Because of suicide inactivation of catechol 2,3-dioxygenase by 3-halocatechols, 1,2-catechol dioxygenase is more often involved in the ring cleavage of aromatics with one or two chlorine substituents (Arora and Bae 2014). In the cells of Stenotrophomonas maltophilia KB2 growing in the presence of phenol the activity of catechol 1,2-dioxygenase was found to be negligible (Guzik et al. 2009).

It has been demonstrated that the composition of fatty acids extracted from S. maltophilia $\mathrm{KB} 2$ differed depending

defined by $\mathrm{PC} 1$ and PC2. 2-CP + P_X-FAMEs isolated from bacteria degrading 2-CP and $\mathrm{P}$; 3-CP $+\mathrm{P} \_\mathrm{X}-\mathrm{FAMEs}$ isolated from bacteria degrading 3-CP and $\mathrm{P}$; 4-CP $+\mathrm{P} \_\mathrm{X}-\mathrm{FAMEs}$ isolated from bacteria degrading 4-CP and $\mathrm{P} ; \mathrm{X}$-sampling day

on the degraded compounds, prior exposure to phenol, and the time of incubation. During the degradation of phenol as a single carbon source bacteria regulated the fluidity of their membranes by the increase in the contents of cyclopropane (17:0 cy, 19:0 cy $\omega 8 c)$ and straight-chain $(12: 0,16: 0)$ fatty acids. The increased abundance of these fatty acids made the membrane less permeable because cyclopropane fatty acids caused a similar effect as increased bilayer thickness, while straight-chain fatty acids made it more rigid through strict packing of their acyl chains (Chen et al. 1995; Grogan and Cronan 1997). It should be noted that the most crucial alterations in fatty acid composition were correlated with the highest activity of catechol 2,3-dioxygenase.

The earlier exposure of $S$. maltophilia KB2 to phenol had a different influence on the composition of cellular 
fatty acids during the co-metabolic degradation of monochlorophenols as compared to unexposed cells. The main difference between these cells was connected with the increase in the abundance of branched fatty acids in the exposed cells. However, this mechanism was not confirmed in the unexposed cells. As Lindström et al. (2006) reported, the incorporation of branched fatty acids in phospholipids stabilizes the gel phase of the membrane bilayers and makes them more rigid. It should be pointed out that branched fatty acids are de novo synthesized, and therefore the described changes in the membrane structure are possible only in growing cells (Fujita et al. 2007). For this reason, their content may be considered as an indicator of the degradation of monochlorophenols by $S$. maltophilia KB2 exposed to phenol. The branched fatty acids are not typical for Gram-negative bacteria. However, their appearance in FAMEs profiles of Gram-negative bacteria under chemical stress in some reports was confirmed (Haack et al. 1994; Mrozik et al. 2005; Nowak and Mrozik 2016). Furthermore, the variability of the cellular fatty acids in dependence to the co-metabolized isomer of monochlorophenols was also connected with the earlier exposure of bacteria to phenol. In the exposed cells this relation was not distinct, while in unexposed ones the most toxic and the most barely degradable 3-CP affected the decrease of membrane permeability through the increased content of straight-chain fatty acids. In turn, in the presence of 2-CP the same effect was achieved by the increase in the content of cyclopropane fatty acids. This dependence was not observed during the co-metabolic degradation of monochlorophenols by Pseudomonas sp. CF600 (Nowak and Mrozik 2016).

In conclusion, the earlier exposure of S. maltophilia KB2 to phenol can accelerate the co-metabolic biodegradation of barely degradable chlorophenols through the induction of required enzymes and correspondent changes in their fatty acid composition. In particular, the changes in the contribution of branched fatty acids in FAME profiles may be proposed as a good indicator of the presence of chlorophenols in the batch cultures. However, further studies are needed to evidence a potential application of this strain in bioremediation of soil and water environments contaminated with chlorophenolic compounds.

Acknowledgments This work was partly supported by National Science Centre N N305 061640.

Open Access This article is distributed under the terms of the Creative Commons Attribution 4.0 International License (http://crea tivecommons.org/licenses/by/4.0/), which permits unrestricted use, distribution, and reproduction in any medium, provided you give appropriate credit to the original author(s) and the source, provide a link to the Creative Commons license, and indicate if changes were made.

\section{References}

Antizar-Ladislao B, Spanova K, Beck AJ, Russel NJ (2008) Microbial community structure changes during bioremediation of PAHs in an aged coal-tar contaminated soil by in-vessel composting. Int Biodeter Biodegr 61:357-364

Arora PK, Bae H (2014) Bacterial degradation of chlorophenols and their derivatives. Microb Cell Fact 13:31-48

Bakhtiar KH, Ahmad MN, Afidah AR (2011) Removal of 4-chloro-2methoxyphenol from aqueous solution by adsorption to oil palm shell activated carbon activated with $\mathrm{K}_{2} \mathrm{CO}_{3}$. J Phys Sci 22:39-55

Balfanz J, Rehm HJ (1991) Biodegradation of 4-chlorophenol by adsorptive immobilized Alcaligenss sp. A 7-2 in soil. Appl Microbiol Biotechnol 35:662-668

Bernal P, Segura A, Ramos JL (2007) Compensatory role of the cistrans-isomerase and cardiolipin synthase in the membrane fluidity of Pseudomonas putida DOT-T1E. Environ Microbiol 9:1658-1664

Bhatkal A, Punage S, Deshannavar UB (2012) Biodegradation of 4-chlorophenol by Pseudomonas putida NCIM sp. 2650 under aerobic conditions. Res J Environ Sci 6:238-244

Brack W, Kind T, Schrader S, Möder M, Schüürmann G (2003) Polychlorinated naphthalenes in sediments from the industrial region of Bitterfeld. Environ Pollut 121:81-85

Bradford MM (1976) A rapid and sensitive method for the quantitation of microgram quantities of protein utilizing the principle of protein-dye binding. Anal Biochem 72:248-254

Caliz J, Vil X, Martí E, Sierra J, Nordgren J, Lindgren PE, Bańeras L, Montserrat G (2011) The microbiota of an unpolluted calcareous soil faces up chlorophenols: evidences of resistant strains with potential for bioremediation. Chemosphere 83:104-116

Chang YY, Cronan JE (1999) Membrane cyclopropane fatty acid content is a major factor in acid resistance of Escherichia coli. Molec Microbiol 33:249-259

Chen O, Nijenhuis A, Preusting H, Dolfing J, Janssen DB, Withold B (1995) Effect of octane on the fatty acid composition and transition temperature of Pseudomonas oleovorans membrane lipids during growth in two-liquid-phase continuous culture. Enzyme Microb Technol 17:647-652

Czaplicka M (2004) Sources and transformations of chlorophenols in the natural environment. Sci Total Environ 322:21-39

Duldhardt I, Gaebel J, Chrzanowski L, Nijenhuis I, Härtig C, Schauer F, Heipieper HJ (2010) Adaptation of anaerobically grown Thauera aromatica, Geobacter sulfurreducens and Desulfococcus multivorans to organic solvents on the level of membrane fatty acid composition. Microb Biotechnol 3:201-209

Fujita Y, Matsuoka H, Hirooka K (2007) Regulation of fatty acid metabolism in bacteria. Mol Microbiol 66:829-839

Gibbons HS, Reynolds CM, Guan Z, Raetz CRH (2008) An inner membrane dioxygenase that generates the 2-hydroxymyristate moiety of Salmonella lipid A. Biochemistry 47:2814-2825

Grogan DW, Cronan JE (1997) Cyclopropane ring formation in membrane lipids of bacteria. Microbiol Mol Biol Rev 61:429-441

Guzik U, Greń I, Wojcieszyńska D, Łabużek S (2009) Isolation and characterization of a novel strain of Stenotrophomonas maltophilia possessing various dioxygenases for monocyclic hydrocarbon degradation. Braz J Microbiol 40:285-291

Haack SK, Garchow H, Odelson DA, Forney LJ, Klug MJ (1994) Accuracy, reproducibility, and interpretation of fatty acid methyl ester profiles of model bacterial communities. Appl Environ Microbiol 60:2483-2493

Hamdaoui O, Naffrechoux E (2007) Modeling of adsorption isotherms of phenol and chlorophenols onto granular activated 
carbon Part I. Two-parameter models and equations allowing determination of thermodynamic parameters. J Hazard Mater 147:381-394

Hao OJ, Kim MH, Seagren EA, Kim H (2002) Kinetics of phenol and chlorophenol utilization by Acinetobacter species. Chemosphere 46:797-807

Hazen TC (2010) Cometabolic bioremediation. In: Timmis KN (ed) Handbook of hydrocarbon and lipid microbiology. SpringerVerlag, Berlin, Heidelberg, pp 2505-2514

Hegeman GD (1966) Synthesis of the enzymes of the mandelate pathway by Pseudomonas putida. J Bacteriol 91:1140-1154

Heipieper HJ, Meinhardt F, Segura A (2003) The cis-trans isomerase of unsaturated fatty acids in Pseudomonas and Vibrio: biochemistry, molecular biology and physiological function of a unique stress adaptive mechanism. FEMS Microbiol Lett 229:1-7

Lee CY, Lee YP (2007) Degradation of 4-chlorophenol by enriched mixed cultures utilizing phenol and glucose as added growth substrate. World J Microb Biot 23:383-391

Li H, Shen TT, Wang XL, Lin KF, Liu YD, Lu SG, Gu JD, Wang P, Lu Q, Du XM (2013) Biodegradation of perchloroethylene and chlorophenol co-contamination and toxic effect on activated sludge performance. Bioresour Technol 137:286-293

Lindström F, Thurnhofer S, Vetter W, Gröbner G (2006) Impact on lipid membrane organization by free branched-chain fatty acids. Phys Chem Chem Phys 8:4792-4797

López-Lara IM, Geiger O (2010) Formation of fatty acids. In: Timmis KN (ed) Handbook of hydrocarbon and lipid microbiology. Springer, Berlin, Heidelberg, pp 385-393

Männistö MK, Tiirola MA, Puhakka JA (2001) Degradation of 2,3,4,6-tetrachlorophenol at low temperature and low dioxygen concentrations by phylogenetically different groundwater and bioreactor bacteria. Biodegradation 12:291-301

Menke B, Rehm HJ (1992) Degradation of mixtures of monochlorophenols and phenol as substrates for free and immobilized cells of Alcaligenes sp. A7-2. Appl Environ Microbiol 37:655-661

Michałowicz J, Duda W (2007) Phenols transformations in the environment and living organisms. Curr Top Biophys 30:24-36

Mrozik A, Piotrowska-Seget Z (2010) Bioaugmentation as a strategy for cleaning up of soils contaminated with aromatic compounds. Microbiol Res 165:363-375
Mrozik A, Łabużek S, Piotrowska-Seget Z (2005) Changes in fatty acid composition in Pseudomonas putida and Pseudomonas stutzeri during naphthalene degradation. Microbiol Res 160:149-157

Mrozik A, Piotrowska-Seget Z, Łabużek S (2007) FAME profiles in Pseudomonas vesicularis during catechol and phenol degradation in the presence of glucose as an additional carbon source. Polish J Microbiol 56:157-164

Murínová S, Dercová K (2013) Bacterial cell membrane adaptation responses on stress caused with the environmental pollutants. Acta Chim Slovaca 6:106-114

Nowak A, Mrozik A (2016) Facilitation of co-metabolic transformation and degradation of monochlorophenols by Pseudomonas sp. CF600 and changes in its fatty acid composition. Water Air Soil Pollut 227:83

Pandey J, Chauhan A, Jain RK (2009) Integrative approaches for assessing the ecological sustainability of in situ bioremediation. FEMS Microbiol Rev 33:324-375

Sasser M (1990) Identification of bacteria by gas chromatography of cellular fatty acids. MIDI Technical Note 101. Newark. DE.: Microbial ID. Inc

Segura A, Bernal P, Pini C, Krell T, Daniels C, Ramos JL (2010) Membrane composition and modifications in response to aromatic hydrocarbons in Gram-negative bacteria. In: Timmis KN (ed) Handbook of hydrocarbon and lipid microbiology. Springer-Verlag, Berlin, Heidelberg, pp 1595-1603

Smułek W, Zdarta A, Guzik U, Dudzińska-Bajorek B, Kaczorek E (2015) Rahnella sp. strain EK12: Cell surface properties and diesel oil biodegradation after long-term contact with natural surfactants and diesel oil. Microbiol Res 176:38-47

Unell M, Kabelitz N, Jansson JK, Heipieper HJ (2007) Adaptation of the psychrotroph Arthrobacter chlorophenolicus A6 to growth temperature and the presence of phenols by changes in the anteiso/iso ratio of branched fatty acids. FEMS Microbiol Lett 266:138-143

Vrchotová B, Loveckà P, Dražkovà M, Mackovà M, Macek T (2013) Influence of root exudates on the bacterial degradation of chlorobenzoic acids. Sci World J 2013:872026

Wojcieszyńska D, Hupert-Kocurek K, Guzik U (2013) Factors affecting activity of catechol 2,3-dioxygenase from 2-chlorophenol-degrading Stenotrophomonas maltophilia strain KB2. Biocatal Biotransfor 2013:1-7 